\title{
Reflections on the Use of Al in the Legal Domain
}

Liane Colonna

The Swedish Law and Informatics Research Institute (IRI), Stockholm, Sweden

Abstract

This paper examines the field of Artificial Intelligence (AI) and Law and offers some broad reflections on its current state. First, the paper introduces the concept of Al, paying particular attention to the distinction between hard and soft Al. Next, it considers how Al can be used to support (or replace!) legal work and legal reasoning. The paper goes on to explore applications of $A$ I in the legal domain and concludes with some critical reflections on the use of Al in the legal context.

Keywords

Artificial intelligence $\cdot$ legal reasoning $\bullet$ legal practice

\section{Introduction}

For many years there has been speculation about "armies of expensive lawyers" being replaced by cheaper software. ${ }^{1}$ While this might be hyperbole, there is little doubt that artificial intelligence is gaining a major stronghold on the profession. ${ }^{2}$ Long gone are the days of antiquated tools like Boolean search, now replaced with data-driven services based on techniques like machine learning. For better or worse, these data-driven algorithms will likely take over major aspects of the knowledge economy once previously thought only capable of being performed by human beings or requiring human intelligence. ${ }^{3}$ With the massive and infallible memory for all court cases, precedents, statutes, case studies, and other legal documents, as well as the ability to scan, analyze, or even reason with these texts, the possibilities for Al and Law appear limitless.

This paper will examine the field of Al and Law which, at its core, "involves the application of computer and mathematical techniques to make law more understandable, manageable, useful, accessible, or predictable." ${ }^{4}$ First, the paper will briefly introduce the concept of Al, paying particular attention to the distinction between hard and soft Al. Next, it will consider how Al can be used to support (or replace!) legal work and legal reasoning. Here, the focus is on understanding the ways computer scientists have been able to represent to computers legal problem-solving strategies as well as legal concepts. The paper goes on to explore applications of $\mathrm{Al}$ in the legal domain. It concludes with some critical reflections on the use of $\mathrm{Al}$ in the legal context.

\section{Artificial Intelligence}

John McCarthy, the father of artificial intelligence, describes it as "the science and engineering of making intelligent machines, especially intelligent computer programs." ${ }^{5} \mathrm{Al}$ is a cluster concept, referring to a constellation of different technologies including, among others, machine learning, deep learning reliant on neural networks, cognitive computing, computer vision and perception, and natural language processing (NLP). ${ }^{6}$ These technologies display intellectual processes characteristic of humans, such as

1 John Markoff, "Armies of Expensive Laywers, Replaced by Cheaper Software," New York Times, March 2011; Rob Toews, "Al Will Transform the Field of Law," Forbes, December 2019.

2 Manveen Singh, "In the Line of Fire: Is Technology Taking over the Legal Profession?," North Carolina Central Law Review 40 (2017): 122, 124-26.

3 Carl Benedikt Frey and Michael A. Osborne, "The Future of Employment: How Susceptible Are Jobs to Computerisation?," Technological Forecasting and Social Change 114 (2017): 254.

$4 \quad$ Harry Surden, "Artificial Intelligence and Law: An Overview," Georgia State University Law Review 35 (2019): 1305, 1326-27.

5 John McCarthy, "What Is Al?/Basic Questions," Stanford University, http://jmc.stanford.edu/artificial-intelligence/what-is-ai/index.html.

6 Raymond T. Nimmer, Law of Computer Technology (Warren Gorham \& Lamont, 2020), § 11:19.30. "Advent of artificial intelligence programs, big data Internet of Things (loT)-General overview."

\footnotetext{
${ }^{\dagger}$ Corresponding author: Liane Colonna
}

E-mail: Liane.Colonna@juridicum.su.se 
the ability to reason, solve problems, or learn from experience. ${ }^{7}$ While some computer programs can match human experts in performing certain specific tasks-like playing chess-there are as yet no systems that fully rival human intelligence. ${ }^{8}$

There is currently no single, universally accepted definition of artificial intelligence, but one way to understand the concept, albeit in a simplistic manner, is to divide it into two camps: hard and soft Al. Hard Al is focused on having machines think like humans. Hard Al would include a program or algorithm that can beat the Turing Test, which states that Al must be able to exhibit intelligent behavior that is indistinguishable from that of a human. ${ }^{9}$ The point at which computers can autonomously outperform even the most intellectually capable humans is referred to as Artificial Super Intelligence (ASI), or more colloquially as "the Singularity." 10 This is the point at which dystopian and apocalyptic visions start to emerge, although not everyone is pessimistic about potential effects of hard ASI on humanity. ${ }^{11}$

Soft $\mathrm{Al}$ is focused on machines being able to do work that traditionally could only be completed by humans. It is focused on system or program design and having the technologies imitate or simulate human thinking and behavior. ${ }^{12}$ The main difference is that soft Al doesn't necessarily involve machines thinking exactly in the same way as humans; the end result, however, is the same. An example of soft Al is Google Translate, where the technology imitates outcome rather than process. ${ }^{13}$

Since the turn of the twenty-first century, Al has started to pervade daily life. Automatic speech recognition systems are increasingly common in smartphones and assistance applications. ${ }^{14}$ Self-driving cars, while not yet standard, use Al-powered safety functions. ${ }^{15} \mathrm{Al}$ is enabling the prediction and treatment of disease. For example, $\mathrm{Al}$ can dramatically improve diagnosis as well as substitute a broad category of family and professional caregiver functions. ${ }^{16} \mathrm{Al}$ is also behind internet search engine algorithms used by millions of people every day in smart homes, cities, and infrastructure, as well as digital personal assistants. ${ }^{17}$ When it comes to knowledge-based industries, Al-based systems have made significant inroads. For example, in the field of journalism, artificial intelligence writes "hundreds of thousands of the articles that are published by mainstream media outlets every week." ${ }^{18}$ Forbes has rolled out an Al-powered Content Management System called Bertie that suggests content and titles, and the Washington Post released Heliograf, an in-house automated storytelling technology that can generate entire articles from quantitative data. ${ }^{19}$

\section{Al, Legal Work, and Legal Reasoning}

At the outset, it is useful to discuss the mental processes a lawyer uses to solve his or her legal problems so that it becomes possible to understand how computers can imitate these behaviors. ${ }^{20}$ Here, four key legal problem-solving processes will be

7 Id.

8 Karl Manheim and Lyric Kaplan, “Artificial Intelligence: Risks to Privacy and Democracy,” Yale Journal of Law and Technology 21 (2019): 106, 113-16.

9 American Medical Association, "Primer on Artificial and Augmented Intelligence," Report of the Council on Long Range Planning and Development (June 2018).

10 Nick Bostrom, Superintelligence: Paths, Dangers, Strategies, 115 (Oxford: Oxford University Press, 2014); for more on the Singularity, see further A. M. Turing, Intelligent Machinery, a Heretical Theory Philosophia Mathematica 4 (1996): 256-60; Vernor Vinge, "First Word," OMNI Magazine (January 1983), 256-60; Ray Kurzweil, The Singularity Is Near: When Humans Transcend Biology (Penguin, 1983) (explaining "(the Singularity is) a future period during which the pace of technological change will be so rapid, its impact so deep, that human life will be irreversibly transformed. Although neither utopian nor dystopian, this epoch will transform the concepts that we rely on to give meaning to our lives, from our business models to the cycle of human life, including death itself. Understanding the Singularity will alter our perspective on the significance of our past and the ramifications for our future. To truly understand it inherently changes one's view of life in general and one's own particular life. I regard someone who understands the Singularity and who has reflected on its implications for his or her own life as a 'singularitarian'.").

11 Nick Bostrom, Superintelligence: Paths, Dangers, Strategies, 115 (Oxford: Oxford University Press, 2014) ("[A] plausible default outcome of the creation of machine superintelligence is existential catastrophe."); but see cf Barry B. Luokkala, "Can a Machine Become Self-Aware?" in: Exploring Science Through Science Fiction. Science and Fiction, ed. Barry B. Luokkala (Cham: Springer 2019) citing H. Robot Moravec, Mere Machine to Transcendent Mind (Oxford: Oxford University Press, 1999), 170 ("The dream of some in the hard Al camp is that we may be able (at some time in the future) to transfer the essence of human consciousness into artificial hardware and achieve immortality, living forever in machine bodies with infinitely replaceable parts.").

12 Raymond S. T. Lee, Artificial Intelligence in Daily Life (Singapore: Springer, 2020).

13 Philip Segal, "Legal Jobs in the Age of Artificial Intelligence: Moving from Today's Limited Universe of Data Toward the Great Beyond," Savannah Law Review 5 (2018): 211, 214.

14 Ruby Arterburn, "What Are the Latest Trends in Speech and Voice Recognition Market?," Fresno Observer, December 2019.

15 European Parliament, "What is artificial intelligence and how is it used?" (9 April 2020), https://www.europarl.europa.eu/news/en/headlines/ society/20200827STO85804/what-is-artificial-intelligence-and-how-is-it-used.

16 Nicolas Terry, "Of Regulating Healthcare Al and Robots," Yale Journal of Health Policy, Law \& Ethics 18 (2019): $133,190$.

17 European Parliament, "What is artificial intelligence and how is it used?" (9 April 2020), https://www.europarl.europa.eu/news/en/headlines/ society/20200827STO85804/what-is-artificial-intelligence-and-how-is-it-used.

18 Calum Chace, "The Impact of Al on Journalism," Forbes, August 2020.

19 Ron Schmelzer, "Al Making Waves in News and Journalism," Forbes, August 2019.

20 Bruce G. Buchanan and Thomas E. Headrick, "Some Speculation About Artificial Intelligence and Legal Reasoning," Stanford Law Review 23 (1970): 51. 
discussed. First, the lawyer establishes and pursues a goal, like seeking some satisfactory legal result for his or her client. ${ }^{21}$ Then, the lawyer uncovers the relevant facts and performs rule selection. ${ }^{22} \mathrm{~A}$ fourth process concerns analogies, that is, fashioning arguments built from cases with facts that are analogous to his or her own in formulating an argument. ${ }^{23}$

Another way to think about this is in terms of legal reasoning. What type of reasoning do lawyers rely upon? Here, there are many different answers, but three major categories emerge: rule-based reasoning, case-based reasoning, and policy-based reasoning. With rule-based reasoning, human beings (or computers!) apply a preexisting rule to a new factual situation. ${ }^{24}$ This kind of reasoning is also referred to as deductive logic. ${ }^{25}$ Rule-based reasoning is what computers engage in when they operate what are generally called "expert systems," or what some would prefer to call a "decision support system." ${ }^{26}$ Pursuant to rulebased models, the law is viewed as an axiomatic system-essentially a group of premises from which legal conclusions can be achieved through logical inference. ${ }^{27}$ Kevin Ashley explains that in developing these models, researchers address questions like "how to represent what a legal rule means so that a computer program can decide whether it applies to a situation." 28 Case-based reasoning occurs when human beings (or machines!) "look for past situations or events with facts similar to those of present problems and then extrapolate the results in those past situations to the present events." ${ }^{29}$ This kind of reasoning is often relied upon when rule-based reasoning cannot solve the problem. ${ }^{30}$ Ashley explains, "A statute can be modeled as a logic program or using heuristic rules, but when the rules run out, resort must be made to something else," like, for example, arguments from cases. ${ }^{31}$ When people or computers engage in case-based reasoning, they first "search their memories for past 'cases' or episodes in which the facts are similar to the facts of present problems or situations." ${ }^{32}$ After identifying past cases with facts similar to those of present problems, "the reasoner decides that what was done as a consequence of the facts in the past case should also be done in connection with the current problem." ${ }^{33}$ In short, case-based models represent legal cases in a manner that permits a computer program to reason over cases by analogy. ${ }^{34}$

Policy-based reasoning involves an examination of the "reasons" or "purposes" behind legal rules and involves a number of subsidiary skills. ${ }^{35}$ It emerged from the British school of utilitarianism and the American philosophy of pragmatism and involves "an ends-means analysis that entails a judicial balancing of the costs and benefits of a legal outcome." ${ }^{36}$ Paul Wangerin explains that policy-based reasoning can be used "both to complement case-based and rule-based reasoning and to contradict such reasoning. ${ }^{37}$ For example, policy-based reasoning can be used to provide definitions for vague words in rules or to provide a test for determining what one should "include in the factual schemata used to search for past cases that are structurally similar to present problems." ${ }^{38}$ Wangerin also explains that policy-based reasoning can be used to complement case-based and rulebased reasoning by providing additional support to an argument based on rules or past cases. ${ }^{39}$

21 Id.

22 Id.

23 Id.; see further Wilson Huhn, "The Stages of Legal Reasoning: Formalism, Analogy, and Realism," Villanova Law Review 48 (2003): 305,312 ("Formalism, in law, is to apply a rule of law to a case because the facts of the case are the same as the terms of the rule. Reasoning by analogy, in contrast, is the application of a rule of law to a case because the facts of the case are similar to the terms of the rule.").

24 Paul T. Wangerin, "A Multidisciplinary Analysis of the Structure of Persuasive Arguments," Harvard Journal of Law \& Public Policy 16 (1993): $195,211$.

25 Id.

26 Philip Leith, "The Rise and Fall of the Legal Expert System," European Journal of Law and Technology 30 (2016): 94,97 (explaining, "A relatively simple idea underpins the notion of a legal expert system: that one can take rules of law, mould them into a computer-based formal system, and advice will come out the other end.").

27 Layman E. Allen and Charles S. Saxon. "A-Hohfeld, A Language for Robust Structural Representation of Knowledge in the Legal Domain to Build InterpretationAssistance Expert Systems," in Deontic Logic in Computer Science, eds. John-Jules Ch. Meyer and Roel J. Wieringa (Chichester, UK: John Wiley and Sons Ltd., 1994), 205-24.

28 Kevin Ashley, Artificial Intelligence and Legal Analytics: New Tools for Law Practice in the Digital Age (Cambridge University Press, 2017):<<AU: PLS SUPPLY PAGE(S)>>

29 Paul T. Wangerin, "A Multidisciplinary Analysis of the Structure of Persuasive Arguments," Harvard Journal of Law \& Public Policy 16 (1993): 195, 212.

30 Id.

31 Kevin D. Ashley, "Teaching Law and Digital Age Legal Practice with an Al and Law Seminar," Chicago-Kent Law Review 88 (2013): $783,803$.

32 Paul T. Wangerin, "A Multidisciplinary Analysis of the Structure of Persuasive Arguments," Harvard Journal of Law \& Public Policy 16 (1993): 195, 212-13.

33 Id.

34 Giuseppe Contissa et al., "Towards Consumer-Empowering Artificial Intelligence," Conference: Twenty-Seventh International Joint Conference on Artificial Intelligence (2018), https://www.ijcai.org/Proceedings/2018/0714.pdf.

35 Wilson Huhn, "The Stages of Legal Reasoning: Formalism, Analogy, and Realism," Villanova Law Review 48 (2003): 305, 316-18 ("Policy analysis comprises a number of subsidiary skills. First, one must imagine the hypothetical consequences of interpreting the law one way or another. Second, one must identify the interest or abstract principle that a rule serves. Third, one must evaluate the weight of that interest or principle. Fourth, one must estimate the likelihood that the rule will accomplish its goal and serve this interest or principle. Finally, one must simultaneously balance the weight and likelihood of all of the 36 Id. competing interests and principles. All of these tasks require the skills that are developed at later stages of cognitive and moral development.")

37 Paul T. Wangerin, "A Multidisciplinary Analysis of the Structure of Persuasive Arguments," Harvard Journal of Law \& Public Policy 16 (1993): 195, 229.

38 Id. at 218.

39 Id. 
Turning to $\mathrm{Al}$ and its relationship with legal research, $\mathrm{Al}$ and Law has been a research field since the 1980s with roots in the previous decades. ${ }^{40} \mathrm{Al}$ and Law researchers build computational models of legal reasoning, which are computer programs that perform or simulate legal reasoning. ${ }^{41}$ Ashley explains, "These computational models are used in building tools to assist in legal practice and pedagogy and in studying legal reasoning in order to contribute to cognitive science and jurisprudence." ${ }^{.22}$ Here, rule-based and case-based programs that can perform intelligent tasks like legal reasoning and argumentation have been a clear focus of study. ${ }^{43}$ Developing models that contain teleological components has also been an important part of the course of $\mathrm{Al}$ and Law research, especially after it was discovered that the underlying purposes or values served by legal statutes and rules were often missing from models. ${ }^{44}$

While rule-based, case-based, and teleological reasoning by computers has steadily progressed during the past 40 years, the reality is that there are unique characteristics about the law and legal reasoning that make it particularly challenging for automation in general and $\mathrm{Al}$ in particular. ${ }^{45}$ For example, legal reasoning is "multi-modal, rich and varied." ${ }^{46}$ It not only includes reasoning with cases, rules, statutes, and principles but sources of law include national laws, special legislation, case law, and provisions established in contracts. ${ }^{47}$ These sources of law are amorphous and change over time ${ }^{48}$ Furthermore, the character of answers in the law often exists on a continuum rather than in binary format, which is much more conducive to automation. ${ }^{49}$ Law often consists of legal rules formulated in general terms containing an "open texture." 50

The knowledge used in legal reasoning is frequently specialized, making it hard to extract requirements directly from texts without misinterpretations. ${ }^{51}$ Statutory structure also affects the meaning of legal rules, and legal rules may have unreferenced exceptions and unstated conditions. ${ }^{52}$ Paul Otto and Annie Antón, two engineers, summarize the challenges: "[w]orking with legal texts can be very challenging . . . because they contain numerous ambiguities, cross-references, domain-specific definitions, and acronyms, and are frequently amended via new statutes, regulations, and case law.".53 As a result of these challenges, labor-intensive, manual representation of legal knowledge has been necessary, resulting in a knowledge acquisition bottleneck that has long hampered progress in fielding intelligent legal applications ${ }^{54}$ In other words, during the development of computerized systems that contain formalized representations of the law, it is almost always necessary to recruit legal experts to gather the relevant legal sources, interpret them, and form valid legal rules. ${ }^{55}$ That said,

40 Kevin Ashley, Artificial Intelligence and Legal Analytics: New Tools for Law Practice in the Digital Age (Cambridge University Press, 2017).

41 Kevin D. Ashley, "Teaching Law and Digital Age Legal Practice with an Al and Law Seminar," Chicago-Kent Law Review 88 (2013): 783.

42 Id.

43 Kevin Ashley, Artificial Intelligence and Legal Analytics: New Tools for Law Practice in the Digital Age (Cambridge University Press, 2017).

44 Kevin D. Ashley, "Teaching Law and Digital Age Legal Practice with an Al and Law Seminar," Chicago-Kent Law Review 88 (2013): 783 citing Donald H. Berman and Carol Hafner, "Representing Teleological Structure in Case-Based Legal Reasoning: The Missing Link," 1993 Proc. of the Fourth Int'I Conf. on Artificial Intelligence \& L. 50., and Trevor Bench-Capon and Giovanni Sartor, A Model of Legal Reasoning with Cases Incorporating Theories and Values, 150 Artificial Intelligence 97 (2003) ("In 1993, an influential critique changed the course of Al and Law research on case-based computational models. Donald $\mathrm{H}$. Berman and Carol Hafner pointed out that the models lacked a teleological component: the underlying purposes or values served by legal statutes and rules--which are so much a focus of human legal interpretation--were missing. The criticism led to a decade of work, resulting in Bench-Capon and Sartor's landmark model of legal reasoning with cases that incorporated values in theories of value preferences induced from precedents.")

45 Edwina L. Rissland, “Artificial Intelligence and Law: Stepping Stones to a Model of Legal Reasoning,"Yale Law Journal 99 (1990): $1957,1961$.

46 Id.

47 Id.

48 Id. ("The character of answers in the law is different from those in many other disciplines: Answers are much more a matter of degree than clear-cut yes-or-no and they can change over time.").

49 Id.

50 H. L. A. Hart, The Concept of Law (2d ed., Oxford: Oxford University Press, 1994), 12-13, 123, 126-29 (attributing "the open texture of law" to the characteristics of language and to "the human predicament," which consists of people's relative ignorance of what the future will bring, that is, the "unenvisioned case.").

51 Ambrosio Toval et al., "Legal Requirements Reuse: A Critical Success Factor for Requirements Quality and Personal Data Protection," Proceedings IEEE Joint International Conference on Requirements Engineering 95, 96 (2002) (discussing the "difficulty of understanding and extracting requirements directly from legal documents" because, inter alia, "legal language is often difficult for non-juristic experts to understand, and thus prone to misinterpretations.").

52 Kevin D. Ashley, "Teaching Law and Digital Age Legal Practice with an Al and Law Seminar," Chicago-Kent Law Review 88 (2013): $783,807$.

53 Paul N. Otto and Annie I. Antón, "Managing Legal Texts in Requirements Engineering," in: Design Requirements Engineering: A Ten-Year Perspective. Lecture Notes in Business Information Processing 374 (Kalle Lyytinen et al. eds., 2009).

54 Kevin Ashley, Artificial Intelligence and Legal Analytics: New Tools for Law Practice in the Digital Age (Cambridge University Press, 2017); see also Giuseppe Contissa et al., "Towards Consumer-Empowering Artificial Intelligence," Conference: Twenty-Seventh International Joint Conference on Artificial Intelligence (2018), https://www.ijcai.org/Proceedings/2018/0714.pdf (explaining "the knowledge representation bottleneck").

55 Dag Wiese Schartum, "From Algorithmic Law to Automation-Friendly Legislation, Computers and Law," in Science Europe, Seven Reasons to Care About Integrity in Research, Science Europe Working Group on Research Integrity eds. Lee Bygrave, E. Dobus, www. Scienceeurope.org; see also Cass R. Sunstein

et al., "Symposium: Legal Reasoning and Artificial Intelligence: How Computers Think Like Lawyers," University of Chicago Law School Roundtable 8 (2001): 1 (explaining, ". . . someone has to represent the facts of the case manually in such a way that the program can know what the facts are and can determine how to analyze the facts."); see also Harry Surden, "Artificial Intelligence and Law: An Overview," Georgia State University Law Review 35 (2019): 1305,1316 (explaining knowledge representation in the context of Al and Law and stating, "Typically, system designers try to translate the knowledge of experts into a series of formal rules and structures that a computer can process."). 
text analytics brings great promise to automate the knowledge representation process. ${ }^{56}$ Instead of relying on the manual extraction of legal knowledge from heterogeneous and dynamic legal sources like statutes, regulations, cases, contracts, and so forth, conducted by experts in the field who encode it as rules, this work can be automatically done by new text analytic techniques. ${ }^{57}$ Some experts believe that $\mathrm{Al}$ and Law is on the eve of a "revolution" as Al learns to read natural language text. ${ }^{58}$ Finally, and relatedly, it is important to mention the role of big data in supporting the development of Al and Law. In particular, big data has given rise to data-centric approaches to legal problem-solving and vastly increased capabilities for the automated interpretation of legal texts. ${ }^{59}$ Laurence Diver explains, "Code-driven applications . . . are tied to the predetermined 'if-then' logical building blocks that underpin all traditional computational systems" whereas "modern data-driven applications are concerned with the use of machine learning algorithms and 'big data' to facilitate automated classification and decisionmaking." ${ }^{\circ 0}$ Currently, the most well-known application of a data-centric technique to the law is the prediction of case outcomes which, notably, does not involve the complex modeling of human legal expertise or generating arguments. ${ }^{61}$ That said, as text mining and other data-centric techniques advance, the possibilities for these more complex applications of Al and Law increase, particularly as they will depend less on manual processes. ${ }^{62}$

\section{Applications of Al in the Legal Domain}

The primary goal of Law and Al is to aid in a new, more advanced form of legal reasoning and argumentation skills of attorneys. ${ }^{63}$ For example, Al can help "retrieve the right cases at the right time" and highlight what is useful about them in the context of an argument. ${ }^{64}$ Another goal is to improve the quality of legal decisions and to strengthen the rule of law, including the quality of justifications of decisions in court opinions. ${ }^{65}$ Here, it may be the case that simply by "trying to formalize legal knowledge in computer-executable fashion" and making "explicit every piece of knowledge that goes into that decision making," it becomes apparent that there are some obvious gaps and discrepancies in the law. ${ }^{66}$ An additional goal of Al and Law is to improve the training and skill of lawyers by supporting the careful reading of legal materials, the precise drafting of legal documents, the rational management of risk, and the efficient management of information. ${ }^{67} \mathrm{Al}$ also helps lawyers do their jobs faster and easier, giving them the opportunity to do more in a reduced period of time. ${ }^{68} \mathrm{~A}$ final goal is to facilitate and enhance access to justice, for example, by reducing the high transaction cost of legal services and expanding access to legal tools. ${ }^{69}$ If one considers the central tasks of a lawyer like transacting, advising, negotiating, representing, and structuring, then it

56 Kevin Ashley, Artificial Intelligence and Legal Analytics: New Tools for Law Practice in the Digital Age (Cambridge University Press, 2017); see also Giuseppe Contissa et al., "Towards Consumer-Empowering Artificial Intelligence," Conference: Twenty-Seventh International Joint Conference on Artificial Intelligence (2018), https://www.ijcai.org/Proceedings/2018/0714.pdf.

57 Giuseppe Contissa et al., "Towards Consumer-Empowering Artificial Intelligence," Conference: Twenty-Seventh International Joint Conference on Artificial Intelligence (2018), https://www.ijcai.org/Proceedings/2018/0714.pdf.

58 Kevin Ashley, Artificial Intelligence and Legal Analytics: New Tools for Law Practice in the Digital Age (Cambridge University Press, 2017).

59 L. Karl Branting, "Artificial Intelligence and the Law from a Research Perspective," ABA SciTech Law (2018): $32,33$.

60 Laurence E. Diver, Digisprudence: The Affordance of Legitimacy in Code-as-Law, (University of Edinburgh Doctoral Thesis, 2019), https://era.ed.ac.uk/ handle/1842/36567.

61 L. Karl Branting, "Artificial Intelligence and the Law from a Research Perspective," ABA SciTech Law (2018): 32,33

62 Id at 35.

63 Kevin Ashley and Tom Gordon, "An Introduction to Artificial Intelligence and Law," ICAIL-2005, available at http://www.Irdc.pitt.edu/Ashley/Mexico\%20Talks/ Ashley-Tutorial05.pdf.<<Ed: Pls link>>

64 Cass R. Sunstein et al., "Symposium: Legal Reasoning and Artificial Intelligence: How Computers Think Like Lawyers," University of Chicago Law School Roundtable 8 (2001): 1.

65 Kevin Ashley and Tom Gordon, "An Introduction to Artificial Intelligence and Law," ICAIL-2005, available at http://www.Irdc.pitt.edu/Ashley/Mexico\%20Talks/ Ashley-Tutorial05.pdf<<Ed: Pls link>>; see more generally Peter Seipel, "Legal Aspects of Information Technology," Computers, Environment and Urban Systems 13 (1989): 201.

66 Cass R. Sunstein et al., "Symposium: Legal Reasoning and Artificial Intelligence: How Computers Think Like Lawyers," University of Chicago Law School Roundtable 8 (2001): 1

67 Kevin Ashley and Tom Gordon, "An Introduction to Artificial Intelligence and Law," ICAIL-2005, available at http://www.Irdc.pitt.edu/Ashley/Mexico\%20Talks/ Ashley-Tutorial05.pdf<<Ed: Pls link>>;

68 Nicole Yamane, "Artificial Intelligence in the Legal Field and the Indispensable Human Element Legal Ethics Demands,"Georgetown Journal of Legal Ethics 33 (2020): 877, 890.

69 Kevin Ashley and Tom Gordon, "An Introduction to Artificial Intelligence and Law," ICAIL-2005, available at http://www.Irdc.pitt.edu/Ashley/Mexico\%20Talks/ Ashley-Tutorial05.pdf; Nicole Yamane, "Artificial Intelligence in the Legal Field and the Indispensable Human Element Legal Ethics Demands," Georgetown Journal of Legal Ethics 33 (2020): 877, 886-87; Catrina Denvir et. al., "The Devil in the Detail: Mitigating the Constitutional \& Rule of Law Risks Associated with the Use of Artificial Intelligence in the Legal Domain," Florida State University Law Review 47 (2019): 29,78 ("To date, much has been said about the capacity for Al tools to aid in facilitating access to justice; either through increasing public knowledge of the law, democratizing access to the legal services market by reducing costs, and/or increasing the capacity of adjudicative institutions to handle claims by making processes more efficient."). 
becomes evident there are many ways that $\mathrm{Al}$ can assist in the field and achieve its goals. ${ }^{70} \mathrm{~A}$ significant amount of legal work concerns the processing of different kinds of transactions. ${ }^{71}$ For example, lawyers draft contracts and wills, obtain licenses, form companies, and so on. ${ }^{72}$ Computer systems that make use of conventional programming techniques have long been produced to assist lawyers engaged in this kind of work. ${ }^{73}$ Today, $\mathrm{Al}$ is revolutionizing contract law, for example, "by helping firms to keep terms and usage consistent in all of their contracts." ${ }^{\prime 4}$ Experts suggest that Al will totally disrupt the way lawyers draft, negotiate, review, and perform under contracts..$^{75}$

Computer systems can be used to simulate, at least in part, the reasoning processes of lawyers. This is where, for example, a legal expert system might come into play which can give an opinion on a difficult legal issue or resolve disputes ${ }^{76}$ Such a system might use heuristic rules to advise on settling product liability claims ${ }^{77}$ or examine divorcing couples' assets to help resolve their property disputes ${ }^{78} \mathrm{~A}$ current example of a rule-based system in the realm of privacy law is a decision-support tool that can be utilized to address the complexity of privacy requirements that exist for a multinational company and to support compliance. ${ }^{79}$ As explained above, as Al advances due to improvements in techniques like text mining, Natural Language Processing, and big-data analytics, it is likely that its capacity to "reason" also will improve.

Negotiating plays a central role in legal work as it is often necessary for lawyers to negotiate with clients, other lawyers, officials, and other parties. ${ }^{80} \mathrm{Here}, \mathrm{Al}$ is capable of observing interactions in real-time and delivering informed recommendations on how to proceed. ${ }^{81} \mathrm{Al}$ also can assist attorneys in devising and assessing strategies and arguments as well as facilitating settlement negotiations in litigation. ${ }^{82}$

Representing clients in courts is often seen as a central occupation of the legal profession. ${ }^{83}$ The level of skills required to present cases before different courts vary considerably. ${ }^{84} \mathrm{Al}$ can play a key role in helping lawyers to plan and present a case ${ }^{85}$ For example, it can assist with expert witness testimony. ${ }^{86}$ Another area where Al promises to assist human decisionmaking in the courtroom concerns aspects concerning judges. Richard Re and Alicia Solow-Niederman explain: "Al already supports many aspects of how judges decide cases, and the prospect of 'robot judges' suddenly seems plausible-even imminent." ${ }^{87}$

Legal work often involves "structuring," understood as the application of law to a particular set of facts. ${ }^{88}$ Clark and Economides explain, "academic lawyers engage in this kind of legal work when they attempt to systematize and add

70 Andrew Clark and Kim Economides, "Computers, Expert Systems, and Legal Processes," in Law, Computer Science, and Artificial Intelligence eds. Ajit Narayanan and Mervyn Bennun (Norwood, N.J.: Ablex, 1991) 3-32.

71 Id at 13

72 Id.

73 Id.

74 Beverly Rich, "How Al Is Changing Contracts," Harvard Business Review, February 2018; see further, Nicole Yamane, "Artificial Intelligence in the Legal Field and the Indispensable Human Element Legal Ethics Demands," Georgetown Journal of Legal Ethics 33 (2020): 881 (explaining, "Contract review is another area in which $\mathrm{Al}$ is starting to make major advancements. Several companies-such as Salesforce, Home Depot, and eBay-use Al technology for contract review in their daily operations.").

75 Helena Haapio and Daniel W. Linna, "Contract Quality and Al: Garbage In, Garbage Out?," World Commerce and Contracting, August 2020, https://journal. iaccm.com/contracting-excellence-journal/contract-quality-and-ai-garbage-in-garbage-out.<<Ed: Pls link>>

76 Edwina L. Rissland, "Artificial Intelligence and Law: Stepping Stones to a Model of Legal Reasoning," Yale Law Journal 99 (1990): 1957,1965 (“One of the earliest steps toward a model of legal reasoning was the use of expert systems ${ }^{31<<0 K ?>>}$ to model certain rule-based aspects of law."); J. C. Smith, "Machine Intelligence and Legal Reasoning," Chicago-Kent Law Review 73 (1998): 277, 317.

77 Donald A. Waterman and Mark A. Peterson, Models of Legal Decisionmaking (Santa Monica, CA: RAND Corporation 1981), 14

78 See Al and the Law, Economist, March 2005), http://www.economist.com.ezp.sub.su.se/node/3714082.<<Ed: Pls link>>

79 S. Pearson, "Addressing Complexity in a Privacy Expert System," in: Information Processing and Management of Uncertainty in Knowledge-Based Systems eds. E. Hüllermeier, R. Kruse, and F. Hoffmann (Heidelberg: Springer 2010).

80 Andrew Clark and Kim Economides, "Computers, Expert Systems, and Legal Processes," in Law, Computer Science, and Artificial Intelligence eds. Ajit Narayanan and Mervyn Bennun (Norwood, N.J.: Ablex, 1991), 3-32, 16.

81 Joe McKendrick, "Now, Al Can Give You an Edge . . . in Negotiations," RT Insights, February 2019, https://www.rtinsights.com/now-ai-can-give-you-an-edgein-negotiations/\#: :text=Noted $\% 20$ entrepreneur\%20Victor\%20Kiam\%20once,a\%20negotiator\%20should\%20observe\%20everything.\&text=Artificial\%20 intelligence $\% 20(\mathrm{Al}) \% 20$ is $\% 20$ capable,the $\% 20$ negotiation $\% 20$ process $\% 20$ as $\% 20$ well.

82 Pamela S. Katz, "Expert Robot: Using Artificial Intelligence to Assist Judges in Admitting Scientific Expert Testimony," Albany Law Journal of Science and Technology 24 (2014): 1, 30.

83 Andrew Clark and Kim Economides, "Computers, Expert Systems, and Legal Processes," in Law, Computer Science, and Artificial Intelligence eds. Ajit Narayanan and Mervyn Bennun (Norwood, N.J.: Ablex, 1991), 3-32, 18.

84 Id.

85 Id.

86 Ed Walters, "Al: Practice, Not Promise, in Law Firms, Al-Based Analysis of Data Is Just Getting Started; Let's Look at the Ways It's Already Been Implemented," Law Prac., January/February 2019, 42, 45.

87 Richard M. Re and Alicia Solow-Niederman, "Developing Artificially Intelligent Justice,"Stanford Technology Law Review 22 (2019): 242.

88 Andrew Clark and Kim Economides, "Computers, Expert Systems, and Legal Processes," in Law, Computer Science, and Artificial Intelligence eds. Ajit Narayanan and Mervyn Bennun (Norwood, N.J.: Ablex, 1991), 3-32, 20. 
critical commentary to an otherwise disorganized and potentially conflicting mass of rules and principles." ${ }^{19}$ Structuring work demands a wide variety of skills and expertise like having deep knowledge about a particular area of law, including an understanding of "technical" legal rules as well as an understanding of judicial and governmental policies and practices..$^{90}$ Clark and Economides further explain that computer systems in general and Al in particular "offer an important means of storing, organizing, and accessing the large quantities of data that are generated and relied upon during the course of structuring work." ${ }^{11}$ This makes the whole process of structuring work easier, faster, and less costly and allows the lawyer to strike a more optimal balance between the need to use time efficiently and the need to achieve confidence in research results. ${ }^{92}$

\section{The End of Lawyers?}

Richard Susskind argues that lawyers are harbingers in the face of a wave of automation now beginning to displace highly skilled white-collar workers. ${ }^{93}$ John McGinnis and Russell Pearce agree and state that "the disruptive effect of machine intelligence" will "trigger the end of lawyers' monopoly." 94 Josh Blackman contends that "In the not-too-distant future, artificial intelligence systems will have the ability to reduce answering a legal question to the simplicity of performing a search. ${ }^{\prime 95}$ Paul Lippe and Daniel Katz conclude that "[o]nce we have fully artificial intelligence enhanced programs . . . there will be no need for lawyers, aside from the highly specialized and expensive large-law-firm variety."96

In the book, The End of Lawyers? Rethinking the Nature of Legal Services, Susskind contends that the provision of legal services either is or will become "commoditized," just as goods once produced by craftspeople have become commoditized, destroying the legal profession, at least in its current form. ${ }^{97}$ In Susskind's view, only a few highly skilled practitioners will retain the role of "expert trusted adviser," while most other lawyers will work within organizations to create and support the online distribution of large quantities of standardized legal services ${ }^{98}$ Basically, Susskind predicts the end of legal services as currently conceptualized, with most lawyers of the future assuming a new role closer to that of a computer support specialist than an attorney and counselor. ${ }^{99}$

Susskind argues that legal work is proceeding through an evolution of five stages: bespoke, standardized, systematized, packaged, and commoditized. ${ }^{100}$ On the left side of that spectrum is "bespoke" (or custom) work, which is highly complex, hand-crafted legal work that is consistent with traditional billing. ${ }^{101}$ The right endpoint is "commoditized" work defined as "an electronic or online legal package or offering that is perceived as a commonplace, a raw material that can be sourced from one of various suppliers." In between, from left to right, are "standardized," "systematized," and "packaged" tasks. ${ }^{102}$ Susskind's theory is that "disrupters" from evolving technology and economic conditions will place most of the services that law firms currently offer into the commoditized category. ${ }^{103}$

Ever since IBM Watson won against humans on the television game show "Jeopardy!," commentators have contended that it will most certainly be able to answer legal questions. ${ }^{104}$ In fact, ROSS, Watson's brother, has been developed by IBM. ${ }^{105}$ ROSS is "the world's first artificially intelligent attorney," and in 2016, he landed a position at New York law firm Baker \& Hostetler

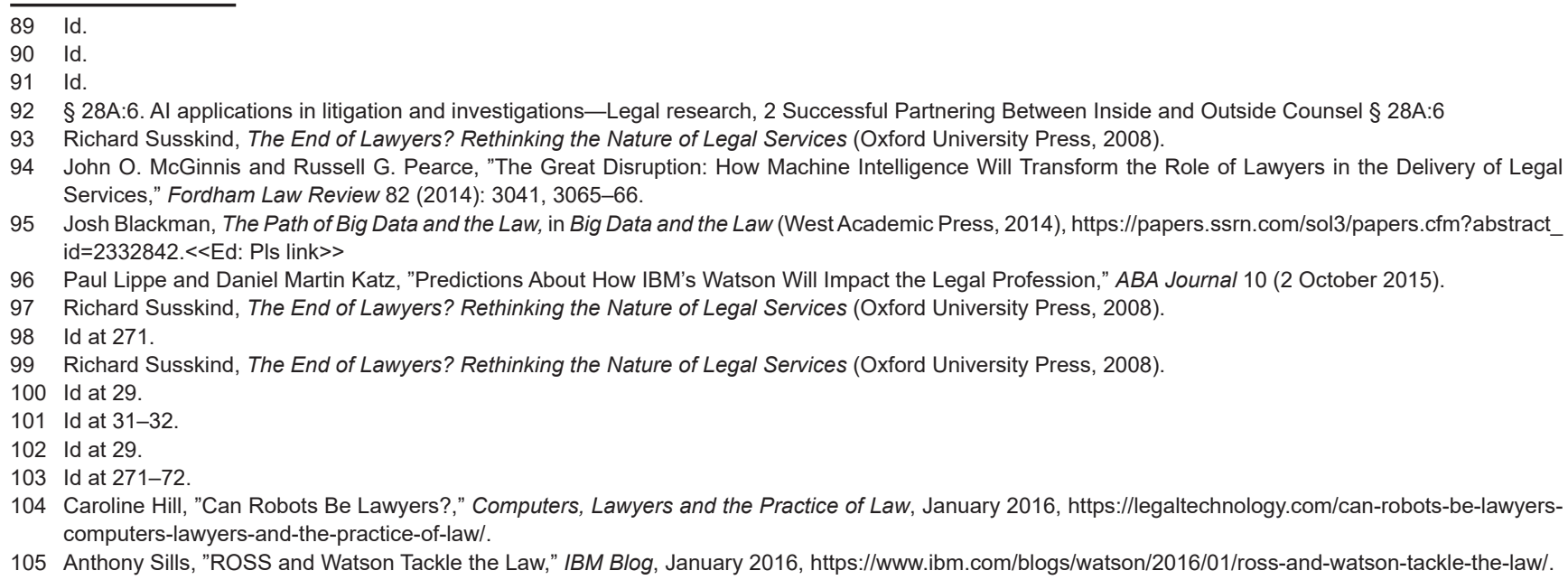


handling the firm's bankruptcy practice. ${ }^{106}$ The machine not only understands language and provides answers to questions, but it also can formulate hypotheses and monitor developments in the legal system. ${ }^{107}$

While some individuals might rejoice in the idea of a world without lawyers, ${ }^{108}$ the reality is that software cannot yet completely take the place of human beings, and so far, lawyers have not been wiped out of the job market in the same way as other types of craftspeople were in the twentieth century. Ostensibly, this has to do with the fact that there are aspects of legal work that cannot be programmed to simulate. Here, Paul Kirgis explains, "The output of lawyers is a stew of intangibles consisting of expertise, judgment, process skills, and the like" which "cannot be formally described." ${ }^{109}$ Legal writing is still very difficult to automate ${ }^{110}$ and expert legal research takes a level of creativity that requires context and pragmatic-level understanding to be performed properly, which also may be hard for Al to replicate. ${ }^{111}$ The role of a Barrister is also a highly personal task that not just involves a clear understanding of specific case details but also key personable and argumentative skills. ${ }^{112}$

Ultimately, the part of lawyering that requires spontaneity, unstructured communication, and emotional intelligence will likely still be highly relevant skills, at least in the few years ahead. For now, the focus on Al will likely be to limit the more mundane functions of a lawyer and to provide more time for lawyers to perform more challenging tasks. ${ }^{113}$ As $\mathrm{Al}$ progresses and, in particular, learns to read legal texts and reason with the information extracted, it will develop its capacity to perform more intellectually rigorous tasks requiring lawyers to evolve their work and adapt accordingly.

\section{Conclusion}

Even though the field of law has always seemed tradition-bound and slow to adopt new technologies, artificial intelligence is beginning to permeate the field and bring major changes to the practice of law. ${ }^{114}$ One of the biggest ways in which Al is influencing knowledge-based disciplines like the law is to force individuals to consider the possibility of nonhuman agencies performing tasks that had hitherto been performed only by human beings. This raises a series of critical questions. Are there some roles that only human beings should fill? Can only humans be lawyers? Can an expert system replicate the functions of judges, whether by mimicking their decision-making process or by a new and better method? Can computers be used to establish the guilt or innocence of a defendant? Is a robot more reliable than a human lawyer or judge? Is there some benefit to taking a human "out of the loop"? Do human lawyers or judges bring something extra to their work? To put it differently, while the use of $\mathrm{Al}$ in the legal field will bring many positive changes like the improvement of the quality of legal services and the increased access to justice, it also will invoke many ethical concerns that require much more extensive study. ${ }^{115}$

106 Karen Turner, "Meet 'Ross,' the Newly Hired Legal Robot," The Washington Post, May 2016, https://www.washingtonpost.com/news/innovations/ wp/2016/05/16/meet-ross-the-newly-hired-legal-robot/?utm_term=.19253d04e756.

107 Navin Bhatia, "New York Law Firm Employs World's First Robot Lawyer," Officechair, May 2016, https://officechai.com/news/robot-lawyer/; see also Nicole Yamane, "Artificial Intelligence in the Legal Field and the Indispensable Human Element Legal Ethics Demands," Georgetown Journal of Legal Ethics 33 (2020): 877, 879 (explaining, "The main way ROSS Intelligence differs from older legal research platforms like LexisNexis and Westlaw is in its ability to generate search results from natural language queries.").

108 See comments section John Markoff, "Armies of Expensive Lawyers, Replaced by Cheaper Software," New York Times, March 2011, http://www.nytimes. com/2011/03/05/science/05legal.html (for example, one comment reads: "Maybe those lawyers and paralegals can quit their blood sucking professions and retrain for something more beneficial to society, like installing solar panels on homes.")

109 Paul F. Kirgis, "The Knowledge Guild: The Legal Profession in an Age of Technological Change," Nevada Law Journal 11 (2010): 184.

110 Dana Remus and Frank Levy, "Can Robots Be Lawyers? Computers, Lawyers, and the Practice of Law," Georgetown Journal of Legal Ethics 30 (2017): 501 , 519.

111 Jamie J. Baker, "2018: A Legal Research Odyssey: Artificial Intelligence as Disruptor," Law Library Journal 110 (2018): 5 , 20.

112 Tom Beattie, "How Will Al Affect the Law?," Portsmouth Point, February 2020, http://portsmouthpoint.blogspot.com/2020/02/how-will-ai-affect-law.html.

113 Id.

114 David Lat, "The Ethical Implications of Artificial Intelligence," Above the Law, February 2020, https://abovethelaw.com/law2020/the-ethical-implications-ofartificial-intelligence.

115 Nicole Yamane, "Artificial Intelligence in the Legal Field and the Indispensable Human Element Legal Ethics Demands," Georgetown Journal of Legal Ethics 33 (2020): 877. 


\section{References}

Allen, Layman E., and Charles S. Saxon. "A-Hohfeld. A Language for Robust Structural Representation of Knowledge in the Legal Domain to Build Interpretation-Assistance Expert Systems." In Deontic Logic in Computer Science, edited by John-Jules Ch. Meyer and Roel J. Wieringa, 205-24. Chichester, UK: John Wiley and Sons Ltd., 1994.

American Medical Association. "Primer on Artificial and Augmented Intelligence." Report of the Council on Long Range Planning and Development. June 2018.

Arterburn, Ruby. "What Are the Latest Trends in Speech and Voice Recognition Market?" Fresno Observer. December 2019.

Ashley, Kevin. Artificial Intelligence and Legal Analytics: New Tools for Law Practice in the Digital Age. Cambridge University Press, 2017.

Ashley, Kevin D. "Teaching Law and Digital Age Legal Practice with an Al and Law Seminar." Chicago-Kent Law Review 88 (2013): 783.

Ashley, Kevin, and Tom Gordon. "An Introduction to Artificial Intelligence and Law." ICAIL-2005, available at http://www.Irdc.pitt.edu/Ashley/ Mexico\%20Talks/Ashley-Tutorial05.pdf.

Baker, Jamie J. "2018: A Legal Research Odyssey: Artificial Intelligence as Disruptor." Law Library Journal 110 (2018): 5.

Beattie, Tom. "How Will Al Affect the Law?," Portsmouth Point, February 2020, http://portsmouthpoint.blogspot.com/2020/02/how-will-ai-affectlaw.html.

Bhatia, Navin. "New York Law Firm Employs World's First Robot Lawyer." Officechair. May 2016, https://officechai.com/news/robot-lawyer/.

Blackman, Josh. "The Path of Big Data and the Law." In Big Data and the Law (West Academic Press, 2014), https://papers.ssrn.com/sol3/ papers.cfm?abstract_id=2332842.

Bostrom, Nick. Superintelligence: Paths, Dangers, Strategies. Oxford: Oxford University Press, 2014.

Branting, L. Karl. "Artificial Intelligence and the Law from a Research Perspective." ABA SciTech Law (2018): 32.

Buchanan, Bruce G., and Thomas E. Headrick. "Some Speculation About Artificial Intelligence and Legal Reasoning." Stanford Law Review 23 (1970): 51.

Chace, Calum. "The Impact of Al on Journalism." Forbes, August 2020.

Contissa, Giuseppe et al. "Towards Consumer-Empowering Artificial Intelligence." Conference: Twenty-Seventh International Joint Conference on Artificial Intelligence (2018), https://www.ijcai.org/Proceedings/2018/0714.pdf.

Denvir, Catrina et al. "The Devil in the Detail: Mitigating the Constitutional \& Rule of Law Risks Associated with the Use of Artificial Intelligence in the Legal Domain." Florida State University Law Review 47 (2019): 29.

Diver, Laurence E. Digisprudence: The Affordance of Legitimacy in Code-as-Law. University of Edinburgh Doctoral Thesis, 2019, https://era. ed.ac.uk/handle/1842/36567.

European Parliament. "What is artificial intelligence and how is it used?" (9 April 2020), https://www.europarl.europa.eu/news/en/headlines/ society/20200827STO85804/what-is-artificial-intelligence-and-how-is-it-used.

Frey, Carl Benedikt, and Michael A. Osborne. "The Future of Employment: How Susceptible Are Jobs to Computerisation?," Technological Forecasting and Social Change 114 (2017): 254.

Haapio, Helena, and Daniel W. Linna. “Contract Quality and Al: Garbage In, Garbage Out?,” World Commerce and Contracting, August 2020, https://journal.iaccm.com/contracting-excellence-journal/contract-quality-and-ai-garbage-in-garbage-out.

Hart, H. L. A. The Concept of Law (2d ed). Oxford: Oxford University Press, 1994.

Hill, Caroline. "Can Robots Be Lawyers?," Computers, Lawyers and the Practice of Law, January 2016, https://legaltechnology.com/canrobots-be-lawyers-computers-lawyers-and-the-practice-of-law/.

Huhn, Wilson. "The Stages of Legal Reasoning: Formalism, Analogy, and Realism." Villanova Law Review 48 (2003): 305.

Katz, Pamela S. "Expert Robot: Using Artificial Intelligence to Assist Judges in Admitting Scientific Expert Testimony." Albany Law Journal of Science and Technology 24 (2014): 1, 30.

Kirgis, Paul F. "The Knowledge Guild: The Legal Profession in an Age of Technological Change." Nevada Law Journal 11 (2010): 184.

Kurzweil, Ray. The Singularity Is Near: When Humans Transcend Biology. Penguin: 1983.

Lat, David. "The Ethical Implications of Artificial Intelligence," Above the Law, February 2020, https://abovethelaw.com/law2020/the-ethicalimplications-of-artificial-intelligence.

Lee, R. S. T. Artificial Intelligence in Daily Life. Singapore: Springer, 2020.

Leith, Philip. "The Rise and Fall of the Legal Expert System." European Journal of Law and Technology 30 (2016): 94.

Lippe, Paul, and Daniel Martin Katz. "Predictions About How IBM's Watson Will Impact the Legal Profession," ABA Journal 10 (2 October 2015 ).

Luokkala, Barry B. "Can a Machine Become Self-Aware?" In Exploring Science Through Science Fiction. Science and Fiction edited by Barry

B. Luokkala. Cham: Springer 2019.

Manheim, Karl, and Lyric Kaplan. "Artificial Intelligence: Risks to Privacy and Democracy." Yale Journal of Law and Technology 21 (2019): 106.

Markoff, John. "Armies of Expensive Lawyers, Replaced by Cheaper Software." New York Times, March 2011. 
McCarthy, John. "What Is AI?/Basic Questions." Stanford University, http://jmc.stanford.edu/artificial-intelligence/what-is-ai/index.html.

McGinnis, John O., and Russell G. Pearce. "The Great Disruption: How Machine Intelligence Will Transform the Role of Lawyers in the Delivery of Legal Services." Fordham Law Review 82 (2014): 3041.

McKendrick, Joe. "Now, Al Can Give You an Edge ... in Negotiations." RT Insights, February 2019.

Nimmer, Raymond T. Law of Computer Technology (Warren Gorham \& Lamont, 2020), § 11:19.30. "Advent of artificial intelligence programs, big data Internet of Things (IoT)—General overview."

Otto, Paul N., and Annie I. Antón. "Managing Legal Texts in Requirements Engineering." In Design Requirements Engineering: A Ten-Year Perspective. Lecture Notes in Business Information Processing 374 edited by Kalle Lyytinen et al. Berlin: Springer, 2009.

Pearson, S. "Addressing Complexity in a Privacy Expert System." In Information Processing and Management of Uncertainty in KnowledgeBased Systems edited by E. Hüllermeier, R. Kruse, and F. Hoffmann. Heidelberg: Springer, 2010.

Re, Richard M., and Alicia Solow-Niederman. "Developing Artificially Intelligent Justice." Stanford Technology Law Review 22 (2019): 242.

Richard Susskind. The End of Lawyers? Rethinking the Nature of Legal Services. Oxford University Press, 2008.

Remus, Dana, and Frank Levy. "Can Robots Be Lawyers? Computers, Lawyers, and the Practice of Law." Georgetown Journal of Legal Ethics 30 (2017): 501

Rich, Beverly. "How Al Is Changing Contracts." Harvard Business Review. February 2018.

Rissland, Edwina L. "Artificial Intelligence and Law: Stepping Stones to a Model of Legal Reasoning." Yale Law Journal 99 (1990): 1957.

Schartum, Dag Wiese. "From Algorithmic Law to Automation-Friendly Legislation, Computers and Law." In Science Europe, seven reasons to care about integrity in research, science Europe working group on research integrity edited by Lee Bygrave and E. Dobus, www. Scienceeurope.org.

Schmelzer, Ron. "Al Making Waves in News and Journalism." Forbes. August 2019.

Segal, Philip. "Legal Jobs in the Age of Artificial Intelligence: Moving from Today's Limited Universe of Data Toward the Great Beyond." Savannah Law Review 5 (2018): 211.

Seipel, Peter. "Legal Aspects of Information Technology." Computers, Environment and Urban Systems 13 (1989): 201.

Sills, Anthony. "ROSS and Watson Tackle the Law," IBM Blog. January 2016, https://www.ibm.com/blogs/watson/2016/01/ross-and-watsontackle-the-law/.

Singh, Manveen. "In the Line of Fire: Is Technology Taking over the Legal Profession?," North Carolina Central Law Review 40 (2017): 122.

Smith, J. C. "Machine Intelligence and Legal Reasoning." Chicago-Kent Law Review 73 (1998): 277.

Sunstein, Cass R., Kevin Ashley, Karl Branting, and Howard Margolis. "Symposium: Legal Reasoning and Artificial Intelligence: How Computers Think Like Lawyers." University of Chicago Law School Roundtable 8 (2001): 1.

Surden, Harry. "Artificial Intelligence and Law: An Overview." Georgia State University Law Review 35 (2019): 1305.

Terry, Nicolas. "Of Regulating Healthcare Al and Robots." Yale Journal of Health Policy, Law \& Ethics 18 (2019): 133.

Toews, Rob. "Al Will Transform the Field of Law." Forbes. December 2019

Toval, Ambrosio et al. "Legal Requirements Reuse: A Critical Success Factor for Requirements Quality and Personal Data Protection." Proceedings IEEE Joint International Conference on Requirements Engineering 95 (2002).

Turing, A. M. "Intelligent Machinery, a Heretical Theory." Philosophia Mathematica 4 (1996): 256-60.

Turner, Karen. 'Meet 'Ross,' the Newly Hired Legal Robot." The Washington Post. May 2016, https://www.washingtonpost.com/news/ innovations/wp/2016/05/16/meet-ross-the-newly-hired-legal-robot/?utm_term=.19253d04e756.

Vinge, Vernor. "First Word." OMNI Magazine. January 1983.

Walters, Ed. "Al: Practice, Not Promise, in Law Firms, Al-Based Analysis of Data Is Just Getting Started; Let's Look at the Ways It's Already Been Implemented." Law Practice. January/February 2019, 42.

Wangerin, Paul T. "A Multidisciplinary Analysis of the Structure of Persuasive Arguments." Harvard Journal of Law \& Public Policy 16 (1993): 195.

Waterman, Donald A., and Mark A. Peterson. Models of Legal Decisionmaking. Santa Monica, CA: RAND Corporation, 1981.

Yamane, Nicole. "Artificial Intelligence in the Legal Field and the Indispensable Human Element Legal Ethics Demands." Georgetown Journal of Legal Ethics 33 (2020): 877 